\title{
Risk Control of Outsourcing in Mobile E-government System
}

\author{
Xiaoyan $\mathrm{Li}^{1,}$, , Likun Zheng ${ }^{2}$, and Shi Wang ${ }^{2}$ \\ ${ }^{1}$ Heilongjiang University of Technology, China \\ ${ }^{2}$ Harbin University of Commerce, China \\ axy_zm123@163.com
}

Keywords: mobile e-government system, outsourcing, risk, analysis, management.

Abstract. E-government system has changed into the direction of deepening service and provided faster and convenient service. With the rapid development of mobile Internet and the popularization of mobile intelligent terminals, mobile e-government is required by citizens for better services. Because of the technical safeguards gap, lack of capital and skilled talents and so on, outsourcing will be applied more generally mobile e-government system. After analyzing outsourcing risks, the author points out effective methods on how to control outsourcing risks and reduce risks to the lowest level.

\section{Introduction}

Government information is the basis of the information society. E-government is the key area of national information infrastructure. E-government system has changed into the direction of deepening service and provided faster and convenient service. With the rapid development of mobile Internet and the popularization of mobile intelligent terminals, mobile e-government is required by citizens for better services. The mobile e-government can promote the government's services and innovative application. It is the inevitable trend of future development. The framework of the mobile e-government and e-government is shown in the Fig1 below.

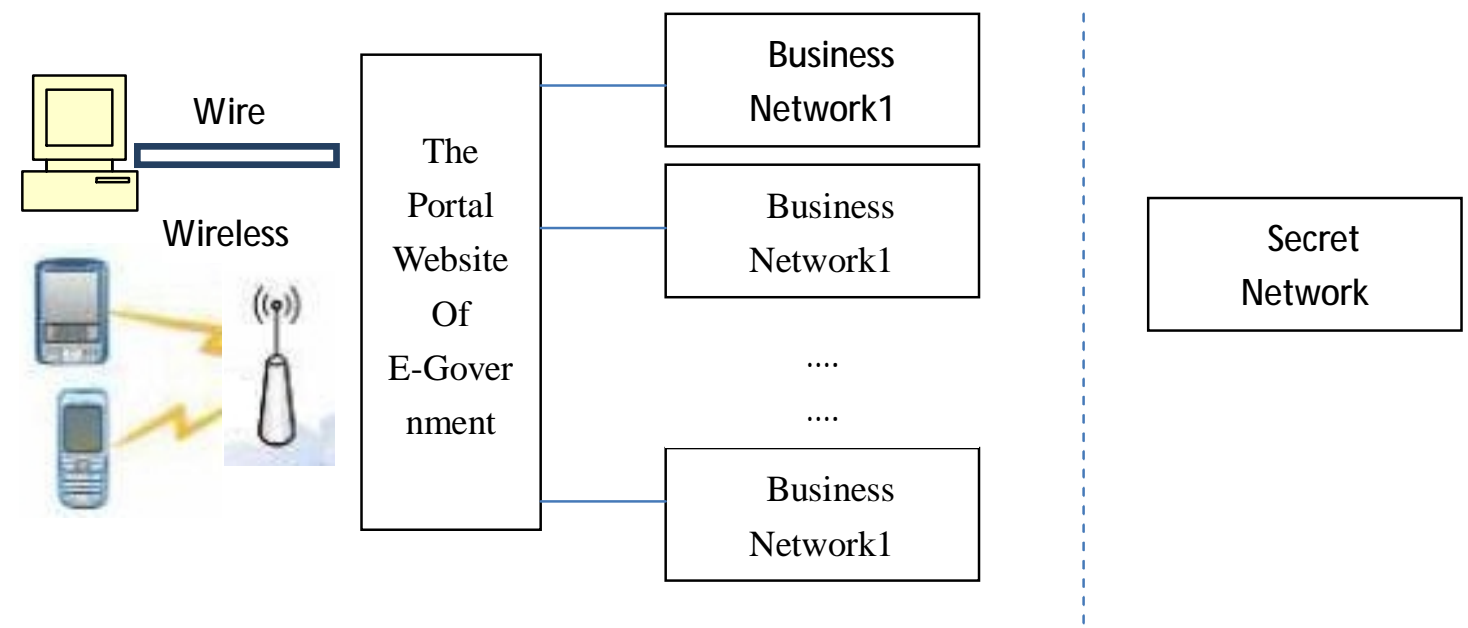

Fig1 The framework of the mobile e-government and e-government

In fact, the mobile e-government is an extension of e-government model and expansion which has been implemented by wired network. It is only a part of e-government. Due to the technical limitations of relevant government staff, the function of the mobile software development must be finished through outsourcing. Outsourcing can save costs, improve efficiency, keep up with technological advancements and overcome technical personnel lacks, meanwhile enable governments at all levels to focus on their core businesses so that they can carry out their official 
roles and functions comprehensively. But there had been a lot of security problems which need to be solved.

\section{Analysis on Outsourcing Risks}

During mobile e-government system outsourcing, outsourcers can exert their advantages on professions and scales to improve security capabilities and service quality of the mobile e-government system and reduce costs. But outsourcers will bring new security risks into the system as well. The mobile terminals of e-government are quite different from the traditional terminal e-government. Its security includes the traditional Internet security problems, the mobile terminal and outsourcing. Therefore, before implementing outsourcing, it must assess relative risks clearly and keep the balance between security costs and risks in order to make reasonable decisions.

At present the main risk of mobile e-government outsourcing faces the following aspects:

Data risk. Due to the outsourcing, some persons or enterprises can understand or know the government agencies network structure, parameter settings and important official data. Because of the limitation of mobile terminal performance and operating environment, it affected the work of data encryption, data integrity and reliability, and mobile system is opened more with wireless, many system reliability and security problems occurred so that many important data process has been leaked, stolen or lost. Because of space limitations display, some transfer methods of the input data and the performance have to be given up.

Business reliance. During the business outsourcing, the person who is in charge of the mobile e-government thinks that anything should be done well and be resolved by the outsourcing provider. If some day the outsourcer operates in an abnormal way, then the business which the outsourcer is responsible for will be most likely to be paralyzed.

Uncontrollable IT Workers. They have no rights to control the staff of the outsourcer to the Government's information management organization. But experienced talents often change their jobs in the IT field, so some outsourcing IT workers cause is bringing unexpected security problems. According to the relative statistics, more security incidents were caused by the internal staff than by viruses and/or hackers from outside. Uncontrollable outsourcing IT workers cause increases system security risks significantly.

Co-operation Failure. The mutual benefit is the cooperation basis between e-government information management agency and outsourcer. It is possible for one of the parties or both of them two to cancel the cooperation between them if they do not have a consensus on costs, managing methods, service or responsibility understandings, etc. The cooperation also will end if the outsourcer develops barriers. Once the cooperation of them failed, it would bring unforeseen risks on business sustainability, data and equipment of compatibility, security, reliability and maintainability to the whole e-government system.

\section{Risk Control of Outsourcing}

Although it is non-existent to do an absolute security on outsourcing, government departments can make different methods and means to reduce risks to the lowest level. The risk control methods of outsourcing is shown Fig2. 


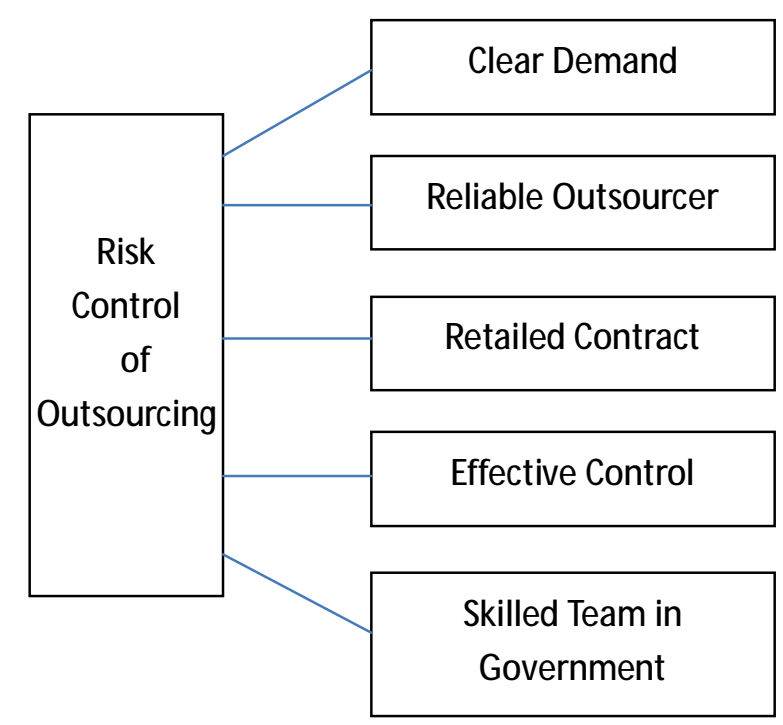

Fig2 The risk control methods of outsourcing

Clear Demand. The mobile e-government is the spread of the existing e-government system. Government staff thinks of exhaustive risks of the mobile system such as the limitation of the mobile terminal and the high risks of wireless and so on. Security factor must be considered first and practical is absolutely the base and the plan should be designed as a whole. Then, try to analyze their own demands on hardware and software resources, staff, budgets and different security requirements comprehensively to meet the needs of the strategy of the e-government development.

Reliable Outsourcer. Reliable outsourcer is an important guarantee that mobile e-government outsourcing can be completed successfully. The reliable outsourcer should provide relative resources and functions for government departments or agencies. Outsourcer business qualifications, his reputation levels, professional technology, management capacity, communicating skills and project plans should be considered carefully when government departments or agencies plan to select outsourcers.

Detailed contract. Outsourcing contracts should be signed in details carefully as much as possible. The contract should include the items below: service scope contents and standards, both sides' rights and responsibilities, reporting procedures, asset ownership, time processing and management procedures, responding time and so on. Information security and secret corresponding for Government rules should be emphasized on items. Detailed contract not only acts as a reference for supervising and inspecting, but also provides an effective legal protection.

Effective Control. Government departments should control and monitor the outsourcing business. It should make records on schedule, track and report the details. It should evaluate what should finish in contract and find the problems and adjust in time if necessary. Through the supervision and management, contracts can be carried out orderly and it can avoid some of risks caused by internal staff so that risks probability is decreased.

Skilled team in Governments. In fact, outsourcing businesses exist some risks. So a skilled team which is subordinate to government departments is needed. They could deal with all the troubles outsourcing businesses might cause. They can not only handle mobile e-government system\& outsourcing plans, organize, manage and coordinate outsourcing businesses well, but also handle emergencies on confidential data and files to ensure e-government systems to work properly. 


\section{Conclusion}

Although security risks of mobile e-government system are adding up and security managements are complicated in outsourcing businesses, mobile e-government system outsourcing risks are controllable and let down through abundant preparations and serious selections. At the same time, mobile e-government system outsourcing can enable governments to provide convenient services for the citizens. Meanwhile mobile e-government will also make the government's daily work and management more efficient and more convenient.

\section{Acknowledgements}

This thesis is a stage achievement of the project (No. 12543049 and No. 12543050) of the Heilongjiang Province Education Bureau. Many people have contributed to it. This thesis will never be accomplished without all the invaluable contributions selflessly from my group members. It is my greatest pleasure and honor working with my group. I'm deeply grateful to them.

\section{References}

[1] Weijing Cao, and Linghong Xia. The Security Management of E-government System in Outsourcing Model. Computer Security. 2008, 8: 104-106

[2] Changsheng Wang, and Xiaoping Xu. Blue Book of E-government.. Social Sciences Academic Press.,pp6-8,76-77. 2013

[3] Xieping Tang. Demand for E-government Survey Application Research of Computers.,7 2008

[4] Information on http://baike.baidu.com/view/65955.htm 